\title{
Clinical and epidemiological data of COVID-19 from Regensburg, Germany: a retrospective analysis of 1084 consecutive cases
}

\author{
Benedikt M. J. Lampl ${ }^{1} \cdot$ Matthias Buczovsky ${ }^{1} \cdot$ Gabriele Martin $^{1} \cdot$ Helen Schmied ${ }^{1} \cdot$ Michael Leitzmann $^{2}$. \\ Bernd Salzberger ${ }^{3}$
}

Received: 27 October 2020 / Accepted: 18 January 2021 / Published online: 5 March 2021

(c) Springer-Verlag GmbH, DE part of Springer Nature 2021

\begin{abstract}
Background COVID-19 is a syndrome caused by the recently emerged SARS-CoV-2. We collected clinical and epidemiologic data in an almost complete cohort of SARS-CoV-2 positive individuals from Regensburg, Germany, from March 2020 to May 2020.

Methods Analysis of a retrospectively documented cohort of consecutive COVID-19 cases recorded between March 7, 2020 and May 24, 2020 as part of an infection control investigation program, with prospective follow-up interviews gathering information on type and duration of symptoms and COVID-19 risk factors until June 26, 2020.

Results Of 1089 total cases, 1084 (99.5\%) cases were included. The incidence during the time period was 315.4/100,000, lower than in the superordinate government district Oberpfalz $(468.5 / 100,000)$ and the overall state of Bavaria (359.7/100,000). The case fatality ratio (CFR) was $2.1 \%$. Among fatal cases, the mean age was 74.4 years and $87 \%$ presented with known risk factors, most commonly chronic heart disease, chronic lung disease, kidney disease, and diabetes mellitus. 897 cases $(82.7 \%)$ showed at least one symptom, most frequently cough (45\%) and fever (41\%). Further, $18 \%$ of cases suffered from odour/taste disorder. $17 \%$ of total cases reported no symptoms. The median duration of general illness was 10 days. During follow-up, 8.9\% of 419 interviewed cases reported at least one symptom lasting at least 6 weeks, and fatigue was the most frequent persistent symptom.

Discussion We report data on type and duration of symptoms, and clinical severity of nearly all (99.5\%) patients with SARSCoV-2 recorded from March 2020 to May 2020 in Regensburg. A broad range of symptoms and symptom duration was seen, some of them lasting several weeks in a considerable number of cases. The case-fatality ratio was $2.1 \%$. Asymptomatic cases may be underrepresented due to the nature of the study.
\end{abstract}

Keywords COVID-19 $\cdot$ Epidemiology $\cdot$ Symptom duration $\cdot$ Risk factors $\cdot$ Infection control

\section{Introduction}

In November 2019, a novel coronavirus (SARS-CoV-2) caused a first outbreak in Wuhan, Hubei, China. Millions of cases of coronavirus disease 2019 (COVID-19) have

Benedikt M. J. Lampl

benedikt.lampl@lra-regensburg.de

$1 \quad$ Public Health Department Regensburg, Germany, University of Regensburg, Altmühlstr. 3, 93059 Regensburg, Germany

2 Department of Epidemiology and Preventive Medicine, Faculty of Medicine, University of Regensburg, Regensburg, Germany

3 Department of Infection Control and Infectious Disease, University of Regensburg, Regensburg, Germany subsequently been reported from all over the world, with more than a million COVID-associated deaths globally [1, 2].

SARS-CoV-2 can cause severe disease, including pneumonia, acute respiratory distress syndrome (ARDS) and multi-organ failure [3]. On the other hand, $90 \%$ of all known infections are mild or moderate [4]. Known risk factors for severe disease are higher age, hypertension, cardiovascular and chronic pulmonary disease, diabetes, immunodeficiency, smoking, male gender [5]. Children might be less often affected than adults [6]. The most frequent symptoms are fever, cough and rhinitis [4]. Data on symptom duration and long-term alterations are incomplete yet.

We present a complete investigation of data on 1,084 consecutive cases of COVID-19 reported in Regensburg, 
Germany. We focus on clinical and epidemiologic data, including frequency and duration of symptoms, risk factors for COVID-19, and characteristics of fatal cases. Information was collected via personal interviews during infection control investigations and follow-up interviews from the first reported case in March 2020 until the end of the wave in May 2020.

\section{Methods}

To study the characteristics and chronology of cases in Regensburg, we analyzed a retrospectively documented cohort of 1084 consecutive COVID-19 cases (by date of reporting) in the city and county of Regensburg, Bavaria from the first reported case on March 7, 2020 through May 24, 2020. The total number of cases in the respective period was 1089; 5 cases were not included due to a delay in reporting.

\section{Case definition}

We applied the case definition according to criteria put forth by the Robert Koch Institute (RKI), the federal government agency responsible for disease control and prevention [7]. Specifically, any validated new positive result of a SARSCoV-2 PCR test reported by a laboratory was regarded as a case. Only new cases were registered. Suspected cases, individuals with a negative PCR result, and those with serological detection of antibodies only or typical morphological alterations in computed tomography only were not considered cases.

\section{Investigations and infection control measures}

All names and contact data of individuals with a SARSCoV-2 positive test result were reported to the Regensburg Public Health Department. Cases were contacted by telephone on the day of reporting and were queried about the type and length of all contacts within the respective period of infectivity ( 2 days before the onset of symptoms until diagnosis). Cases and close contact persons meeting RKI's definition [8] were quarantined on the basis of the RKI recommendations. Cases were quarantined for at least 14 days from symptom onset.

\section{Data collection}

The chronology of cases was depicted as epidemic curve. Case numbers were calculated as incidence per 100,000 per day. During the first peak phase of the SARS-CoV-2 pandemic, data were collected in parallel to infection control and containment measures. A first dataset comprised 1084 consecutive cases and was compiled using a telephone interview, during which information was collected on age, sex, symptoms (fever, cough, rhinitis, headache, fatigue, myalgias/arthralgias, shivering, sore throat, dyspnoea, odour or taste disorders, nausea and diarrhoea), exposure, hospitalisation, and the presence of COVID-19 risk factors (chronic lung disease, asthma, chronic heart disease, diabetes, immunosuppression, neuromuscular disease, pregnancy).

A second dataset was obtained using an additional telephone interview in a sub-sample of 419 of the 1,084 original cases we were able to contact by phone. Cases were eligible for phone calls when at least 6 weeks after the onset of symptoms had passed. Interviews were performed between June 1, 2020 and June 26, 2020 and gathered additional information on the type and duration of symptoms, and possible risk factors. Due to limited resources, only one attempt was made to contact cases by phone.

Informed consent for anonymized data collection was provided by all participants. After the data collection was completed, all data were completely anonymized and analyzed. The study protocol was approved by the ethics committee of the University of Regensburg (Nr. 20-2067-104).

\section{Statistical analysis}

Statistical analyses were conducted using non-parametric methods. In particular, we tested whether the median value differed between groups using the Wilcoxon rank-sum test. All analyses were performed using Microsoft Excel 2016 and the statistical software $R$ 3.6.2.

\section{Results}

A total of 1089 cases were reported to the Public Health Department Regensburg between March 7, 2020 (date of report of the first case in Regensburg, symptom onset on February 2, 2020) and May 24, 2020. Overall, an incidence of 315.4 cases $/ 100,000$ was noted during that time period (Fig. 1). The mean incidence per day in the considered period was 4.0 cases per 100,000 . Furthermore, fatal cases are shown by date of death as absolute numbers. The shown numbers represent only cases of persons resident within the city or county of Regensburg.

The epidemic curve shows a steady increase in cases throughout the beginning of April 2020, with a peak incidence of 14.2 cases per 100,000 on April 1, 2020. Subsequently, the number of new cases decreased in a stepwise fashion until the second half of May. Peak numbers on May 20, 2020 and May 24, 2020 represent outbreaks in facilities for asylum seekers and were due to intensified testing of contact persons. There were smaller local outbreaks in nursing homes, asylum seekers' homes, and a major outbreak in the 


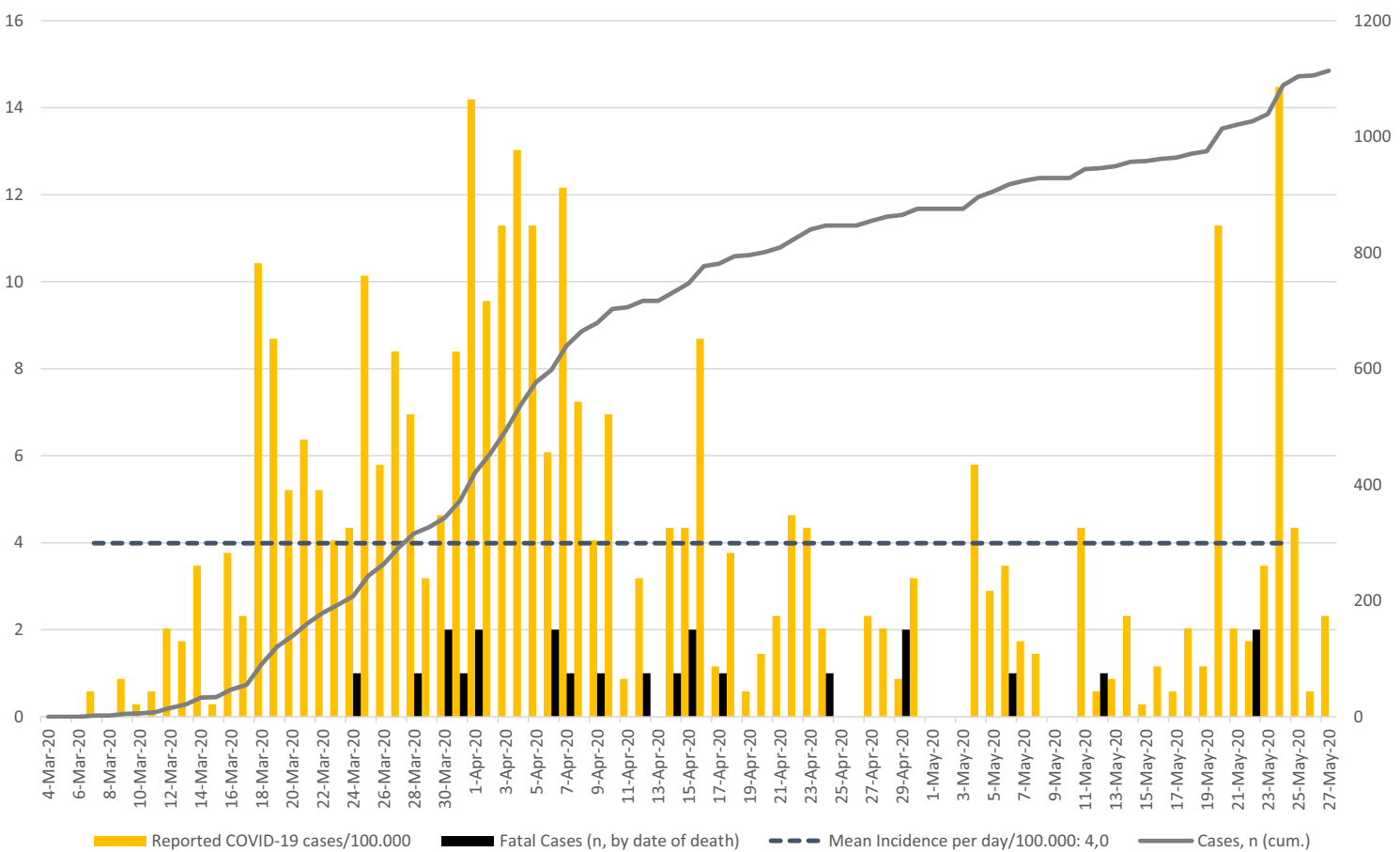

Fig. 1 Epidemic Curve of COVID-19 cases in Regensburg (city and county) from March 7, 2020 to May 24, 2020 (calculated on demographic data from $[14,15]$

University Children's Hospital (including 36 cases among medical personnel) during the reported time period [9].

\section{Dataset I}

Characteristics of 1084 analysed cases are shown in Table 1.

\section{Exposure}

A total of 470 of 1084 cases (43.4\%) reported having had contact with a SARS-CoV-2-positive person, and 107 cases (9.9\%) indicated having travelled within 14 days prior to symptom onset. 382 cases (35.2\%) worked or lived in healthcare/nursing/childcare/asylum seekers' facilities (institutions according to $\S 23, \S 33$ or $\S 36$ of the German Infection Protection Act [Infektionsschutzgesetz, IfSG]).

\section{Data on age and sex distribution, age-specific attack rates and proportion of hospitalized patients}

Of the 1.084 consecutive patients, the mean age was 43 years, $50 \%$ were female, and $59.3 \%$ were city residents. Figure 2 shows the age and sex distribution of cases in absolute numbers and as a proportion of cases. Approximately seventy percent of cases were reported in patients between 21 and 60 years of age, and 19\% of cases was aged over age 60 years. The proportion of initially asymptomatic persons was $17 \%$ (onset manifestation index: $83 \%$ ). In $13 \%$ of cases, the onset of symptoms could not be determined.

During the study period, a total of 1,842 close contact persons (category I according to RKI, infection suspects) were investigated and quarantined, of which 171 persons tested positive in PCR. This equals an overall secondary attack rate of $9.3 \%$ in our cohort. Figure S1 (supplementary materials) depicts the age-specific attack rates by 10 -year age categories. Low attack rates were noted for children, with linearly increasing numbers for those above the age of 60 years. Of 171 cases among close contact persons, 113 (66\%) lived together with a known case in one household. Based on 106 cases (62\%), the mean serial interval was $5.9 \mathrm{~d}$ (SD: 4.45; median: $5 \mathrm{~d}$, IQR: 3-8.25 d). The interval from symptom onset to diagnosis was significantly longer in infected close contact persons than in index cases (median 7 versus $5 \mathrm{~d}$; $\mathrm{p}<0.00001$ ).

Figure 3 depicts case numbers, hospitalizations (as officially reported to the Public Health department until October 5,2020$)$ and age related case fatality ratios (CFR) in the considered period. A total of 154 cases (14.2\%) were hospitalized. There were no reported hospitalizations in the age group 11 to 20 years, whereas the greatest proportion of hospitalizations $(69.7 \%)$ were noted in the group aged 81 to 90 years. A linear increase in hospitalizations over time was seen in patients aged 31 to 40 years and those aged 81 to 90 years 
Table 1 Characteristics of all (middle column) and fatal (right column) cases in the Regensburg area

\begin{tabular}{|c|c|c|}
\hline$n(\%)$ & $1084(100)$ & $23(2.1)$ \\
\hline \multicolumn{3}{|l|}{ Sex } \\
\hline Male $[n](\%)$ & $542(50)$ & $15(65.2)$ \\
\hline Female $[n](\%)$ & $542(50)$ & $8(34.8)$ \\
\hline Mean/median age (IQR) [years] & $43.1 / 42(28-57)$ & $74.4 / 78(63-85)$ \\
\hline \multicolumn{3}{|l|}{ Residence } \\
\hline City $[n](\%)$ & $643(59,3)$ & $8(34,8)$ \\
\hline County $[n](\%)$ & $441(40,7)$ & $15(65,2)$ \\
\hline Initially hospitalized & $163(15)$ & $20(87)$ \\
\hline Duration of disease (onset - death) [d] & - & $\begin{array}{l}\text { Mean: 16,7 (median 12; } \\
\text { IQR: } 2 \text { - 33; Max.: } \\
\text { 59) }\end{array}$ \\
\hline Onset of disease unknown & $142(13.1)$ & $4(17.4)$ \\
\hline \multicolumn{3}{|l|}{ Symptoms initially $[\mathrm{n}](\%)$} \\
\hline any & $897(82.7)$ & $20(87)$ \\
\hline Cough & $490(45)$ & $12(52.2)$ \\
\hline Fever & $443(41)$ & $8(34.8)$ \\
\hline Headache & $310(29)$ & $0(0)$ \\
\hline Myalgias/arthralgias & $238(22)$ & $1(4.3)$ \\
\hline Fatigue & $210(19)$ & $7(30.4)$ \\
\hline Sore Throat & $208(19)$ & $3(13)$ \\
\hline Odour or taste disorders & $194(18)$ & $1(4.3)$ \\
\hline Rhinitis & $151(14)$ & $1(4.3)$ \\
\hline Dyspnoea & $109(10)$ & $8(34.8)$ \\
\hline Shivering & $105(10)$ & $1(4.3)$ \\
\hline Diarrhoea & $49(5)$ & $3(13)$ \\
\hline Nausea & $44(4)$ & $1(4.3)$ \\
\hline \multicolumn{3}{|l|}{ Exposure $[\mathrm{n}](\%)$} \\
\hline Contact with a known case & $470(43.4)$ & $5(21.7)$ \\
\hline History of Travel & $107(9.9)$ & $0(0)$ \\
\hline Living with other persons in one household & $800(73.8)$ & $20(87)$ \\
\hline \multicolumn{3}{|l|}{ Risk factors $[\mathrm{n}](\%)$} \\
\hline Overall & $304(28)$ & $20(87)$ \\
\hline Chronic heart disease & $109(10.1)$ & $12(52.2)$ \\
\hline Chronic lung disease & $73(6.7)$ & $5(21.7)$ \\
\hline Diabetes mellitus & $49(4.5)$ & $3(13)$ \\
\hline Chronic kidney disease & $21(1.9)$ & $4(17.4)$ \\
\hline Cancer & $15(1.4)$ & $3(13)$ \\
\hline Immunosuppression & $13(1.2)$ & $2(8.7)$ \\
\hline None & $717(66.1)$ & $3(13)$ \\
\hline
\end{tabular}

The proportion of initially hospitalized patients was 36\% in patients with dyspnoea, and $13 \%$ in patients without dyspnoea. Thus, the relative risk of hospitalization with dyspnoea at the time of symptom onset was 2.77 compared to patients without dyspnoea. The frequency of initial hospitalization was $24 \%$ when risk factors were present, and $8 \%$ when they were absent. This corresponds to a threefold increased relative risk of hospitalization in the presence of risk factors. Fatalities increased with age, starting with the youngest case aged 51 years.

\section{Fatal cases}

23 COVID-19-related deaths occurred in the reported period (characteristics shown in Table 1). Based on a total of 1084 cases, this equals a CFR of $2.1 \%$ for the city/county of Regensburg. There were twice as many fatal cases among men as women (15 [65.2\%] vs. 8 [34.8\%]). The most frequently reported symptom among fatal cases was cough (52.2\%), whereas fever and dyspnoea were reported by only $34.8 \%$ of patients. Of 23 fatal cases, $20(87 \%)$ reported 
Fig. 2 Age and sex distribution of the Regensburg cases. Cases per 100.000: calculation according to [26], numbers combined for city/county of Regensburg. Percentages are related to all reported cases
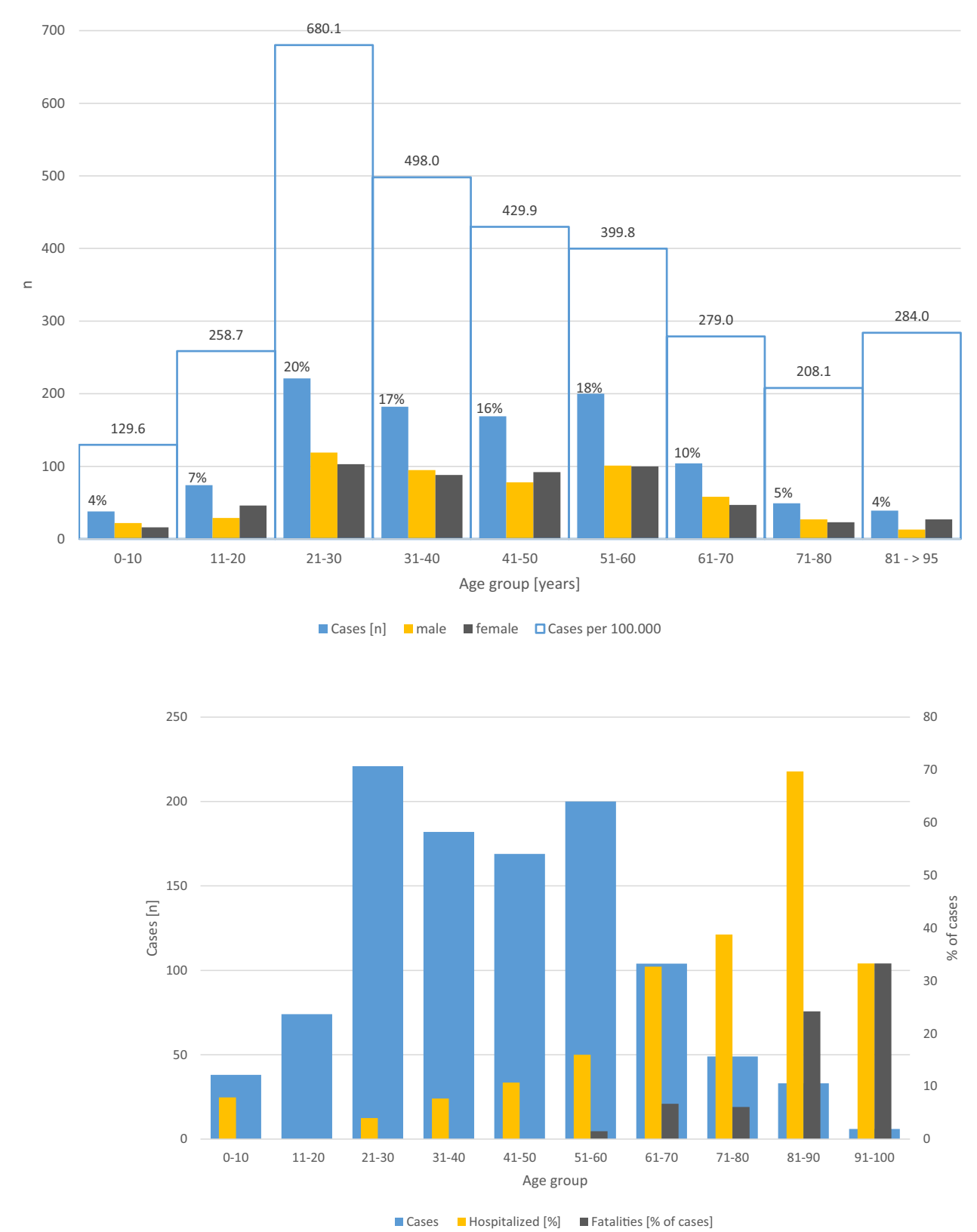

- Cases Mospitalized [\%] - Fatalities [\% of cases]
Fig. 3 Case numbers, proportion of hospitalized patients and fatalities per age group having comorbidities or other risk factors, most frequently chronic heart disease, chronic lung disease, diabetes mellitus and kidney disease. Twenty of 23 patients (87\%) were hospitalized. None of the fatal cases was reported to be a nursing home resident. The duration of disease (symptom onset to death) varied considerably (median 12 days, IQR: 2-33 days, maximum 59 days).

Data on incidence and fatalities were compared with other regional and international data (Table S1, supplementary materials) [1, 10-19]. In Regensburg, the incidence was lower than in the whole of Oberpfalz and Bavaria. In heavily affected Tirschenreuth, a county located approximately $100 \mathrm{~km}$ north of Regensburg, the incidence was 5 times as high and the CFR was approximately 5.5 times as high as in Regensburg. Figure S2 (supplementary materials) shows cases (A) and fatalities (B) of Regensburg, Tirschenreuth, Oberpfalz and Bavaria by age group. In Regensburg, comparably more persons of younger age were affected (20-29 years and 30-39 years), whereas in Tirschenreuth, persons aged 70-79 years and 80-89 years were more frequently affected. Surprisingly, the highest CFR of $43.5 \%$ was noted there in the age group 60-69 years. In Tirschenreuth, younger people aged 20-49 years also died from the disease, whereas in Regensburg fatal cases did not occur below the age of 50 . 


\section{Symptoms}

The most common symptoms were cough (45\%) and fever (41\%). By comparison, gastrointestinal symptoms (diarrhoea/vomitus) were seldomly reported (9\%). $18 \%$ of subjects suffered from odour/taste disorder, and $17 \%$ reported no symptoms in the initial interview. Odour/taste disorder occurred with different frequencies across age groups. It was most common in the group aged 31 to 40 years, with a proportion of $27 \%$ of all cases. Figure S3 (supplementary materials) shows the frequency of reported symptoms by age group at the time of the first interview. Symptoms were generally less frequently reported in the age group 0-10 years and in those aged over 80 years. Fever appeared to be the leading symptom in all age groups, with cough being less frequently reported in the very young and the very elderly.

\section{Dataset II}

A total of 419 of 834 eligible patients responded to the telephone interview performed from June 1, 2020 to June 26, 2020 using a standardized questionnaire (case characteristics, Table 2).

\section{Frequency and duration of Symptoms}

The frequency and duration of symptoms are shown in Table 2, common symptoms are depicted in Fig. S4 (supplementary materials). Of 419 participants, 15 (3.6\%) did not report any symptoms, 3 complained about feeling ill persisting up to the time of the interview. The duration of feeling ill was determined in 385 cases, and the status of the remaining patients was unclear. The average duration of illness in these patients was 12.7 days (median 10). 50\% of the patients showed a duration of illness between 4 and 17 days (interquartile range, $\mathrm{IQR}=13$; maximum duration of symptoms reported: 91 days).

In the follow-up interview, fatigue was the most commonly reported symptom, followed by odour/taste disorder and fever. The median duration of symptoms ranged from 2.5 days (diarrhoea) to 12 days (skin changes). The shortest IQR was observed for myalgias/arthralgias (3 to 7.15 days). Fever duration was quite short (median: 4 days, IQR: 2 to 7 days), whereas cough lasted considerably longer (median 10 days, IQR: 4 to 14 days). All displayed symptoms showed considerable outliers concerning their duration.

A relevant proportion of cases (8.9\%) reported at least one persistent symptom when interviewed after at least 6 weeks (Fig. 4). Odour/taste disorder, dyspnoea, cough and fatigue were the most common symptoms. Odour/taste disorder was reported by 37 patients $(13.5 \%$ of all patients having answered the symptom "yes"or $8.9 \%$ of all patients interviewed). Skin changes occurred rather rarely but lasted longer than six weeks in $15.7 \%$ of persons.

\section{Discussion}

Our study represents the first nearly complete investigation of COVID-19 symptoms and disease severity from a major city and county in Eastern Bavaria. It provides insights into relevant clinical and epidemiologic features of COVID-19. Our results contribute to a more detailed understanding of age-specific characteristics of the disease while confirming data from other regions [20].

The highest incidence was observed on April 1, 2020, one week after a step up in restriction measures were implemented. On the other hand, $\mathrm{R}_{\mathrm{e} \text { Bavaria }}$ (effective reproduction number for Bavaria) was below 1 by mid-March at the latest, according to Nowcasting performed for Bavaria [21]. In Regensburg, infected persons were younger than in Oberpfalz or Bavaria, the age group 21-30 years accounted for the largest share $(20 \%)$ and $70 \%$ of cases were below or at the age of 60 . The proportion of patients 70 years or older was considerably lower than in highly affected Tirschenreuth county or the whole of Oberpfalz and Bavaria.

Around $15 \%$ of cases in our cohort were hospitalized. Initially, information on hospitalization was taken from the first interview, whereas data on overall hospitalizations until 10/2020 are based on hospital reports, both of which may be incomplete. Nonetheless, most cases were hospitalized initially or were not hospitalized at all. An almost linear increase in proportions of hospitalized patients with age can be observed. The overall secondary attack rate of 9.3\% in Regensburg is based on reported cases. Given our strict definition of a close contact person, this figure possibly represents an overestimation. An almost linear increase in the attack rate with age is consistent with other reports [22]. These data are based on the assumption of linear spreading from known cases, which is certainly debatable for SARS$\mathrm{CoV}-2$. Household members appear to have a higher risk of infection [23]. Among household members, we observed a longer symptom-onset-to-diagnosis interval, which could be due to reduced PCR testing capacity at the beginning of the pandemic.

In the Regensburg outbreak, the CFR of $2.1 \%$ was lower than the national or state average. Presumably, a greater proportion of young people and a lower proportion of persons above 70 years of age are responsible for the low CFR in Regensburg. The absence of larger outbreaks in nursing/ retirement homes as well as a different distribution of risk factors are likely to have contributed to this effect. Fatalities in the considered period occurred in elderly patients with risk factors, though underreporting is possible. Other biological factors as contributing factors remain unclear. 
Table 2 Case characteristics dataset 2 (follow-up interviews)

\begin{tabular}{|c|c|c|}
\hline Interview period & $01 / 06 / 2020$ to $26 / 06 / 2020$ & \\
\hline Participants $[n](\%)$ & 419 of 834 eligible patients $(50,2)$ & \\
\hline \multicolumn{3}{|l|}{ Residence } \\
\hline City $[n](\%)$ & $221(52.7)$ & \\
\hline County $[n](\%)$ & $198(47.3)$ & \\
\hline \multicolumn{3}{|l|}{ Sex } \\
\hline Male $[n](\%)$ & $182(43.4)$ & \\
\hline Female $[n](\%)$ & $237(56.6)$ & \\
\hline Mean/median age (IQR) [years] & $44.6 / 44(30-57)$ & \\
\hline Subjective recovery at time of interview $[n](\%)$ & $406(96.4)$ & \\
\hline Prevalence of potential risk factors $[n](\%)$ & Reported & Not reported \\
\hline ACE-Inhibitors & $21(5.2)$ & $385(94.8)$ \\
\hline Smoking & $50(12.0)$ & $367(87.5)$ \\
\hline $\mathrm{BMI}>30 \mathrm{~kg} / \mathrm{m}^{2}$ & $69(16.7)$ & $344(83.3)$ \\
\hline Allergies & $148(35.7)$ & $263(63.4)$ \\
\hline Symptoms (by order of frequency) & {$[n](\%)$} & $\begin{array}{l}\text { Median Duration; } \\
\text { Maximum } \\
\text { [days] }\end{array}$ \\
\hline General feeling Ill & $\begin{array}{l}\text { Yes: } 388(92,2) \\
\text { No: } 15(3,6)\end{array}$ & $10 ; 91$ \\
\hline Fatigue & $\begin{array}{l}\text { Yes: } 321(77,3) \\
\text { No: } 94(22,7)\end{array}$ & $14 ; 63$ \\
\hline Odour/taste disorders & $\begin{array}{l}\text { Yes: } 274(66) \\
\text { No: } 141(34)\end{array}$ & $7 ; 75$ \\
\hline Fever & $\begin{array}{l}\text { Yes: } 232(55,8) \\
\text { No: } 184(44,2)\end{array}$ & $4 ; 77$ \\
\hline Headache & $\begin{array}{l}\text { Yes: } 228(54,9) \\
\text { No: } 187(45)\end{array}$ & $10 ; 49$ \\
\hline Cough & $\begin{array}{l}\text { Yes: } 216(51,8) \\
\text { No: } 201(48,2)\end{array}$ & $10 ; 63$ \\
\hline Myalgias/arthralgias & $\begin{array}{l}\text { Yes: } 191(46,1) \\
\text { No: } 223(53,9)\end{array}$ & $5 ; 56$ \\
\hline Dyspnoea & $\begin{array}{l}\text { Yes: } 163(39,3) \\
\text { No: } 252(60,7)\end{array}$ & $7 ; 90$ \\
\hline Sore throat & $\begin{array}{l}\text { Yes: } 132(31,8) \\
\text { No: } 283(68,2)\end{array}$ & $5 ; 90$ \\
\hline Shivering & $\begin{array}{l}\text { Yes: } 131(31,6) \\
\text { No: } 284(68,4)\end{array}$ & $3 ; 28$ \\
\hline Rhinitis & $\begin{array}{l}\text { Yes: } 118(28,4) \\
\text { No: } 297(71,6)\end{array}$ & $7 ; 63$ \\
\hline Discomfort of the eyes & $\begin{array}{l}\text { Yes: } 113(27,4) \\
\text { No: } 300(72,6)\end{array}$ & No data \\
\hline Dizziness & $\begin{array}{l}\text { Yes: } 101(24,4) \\
\text { No: } 313(75,6)\end{array}$ & $7 ; 49$ \\
\hline Diarrhoea & $\begin{array}{l}\text { Yes: } 95(22,9) \\
\text { No: } 320(77,1)\end{array}$ & 2,$5 ; 40$ \\
\hline Skin changes & $\begin{array}{l}\text { Yes: } 51(12,2) \\
\text { No: } 366(87,8)\end{array}$ & $12 ; 56$ \\
\hline Nausea & $\begin{array}{l}\text { Yes: } 49(11,8) \\
\text { No: } 366(88,2)\end{array}$ & 3,$5 ; 28$ \\
\hline
\end{tabular}

Of the initial 25 cases in Regensburg, 13 had a history of traveling/skiing (11 in Italy, of which 8 were in Trentino/South Tyrol). Many of the initial cases in Regensburg may have been linked to the Bavarian winter holidays
(24/02 to 28/02/2020) or the skiing season. The absence of a major spreading event, however, may have contributed to lower case numbers and to a lower CFR. 
Fig. 4 Proportion of persistent symptoms

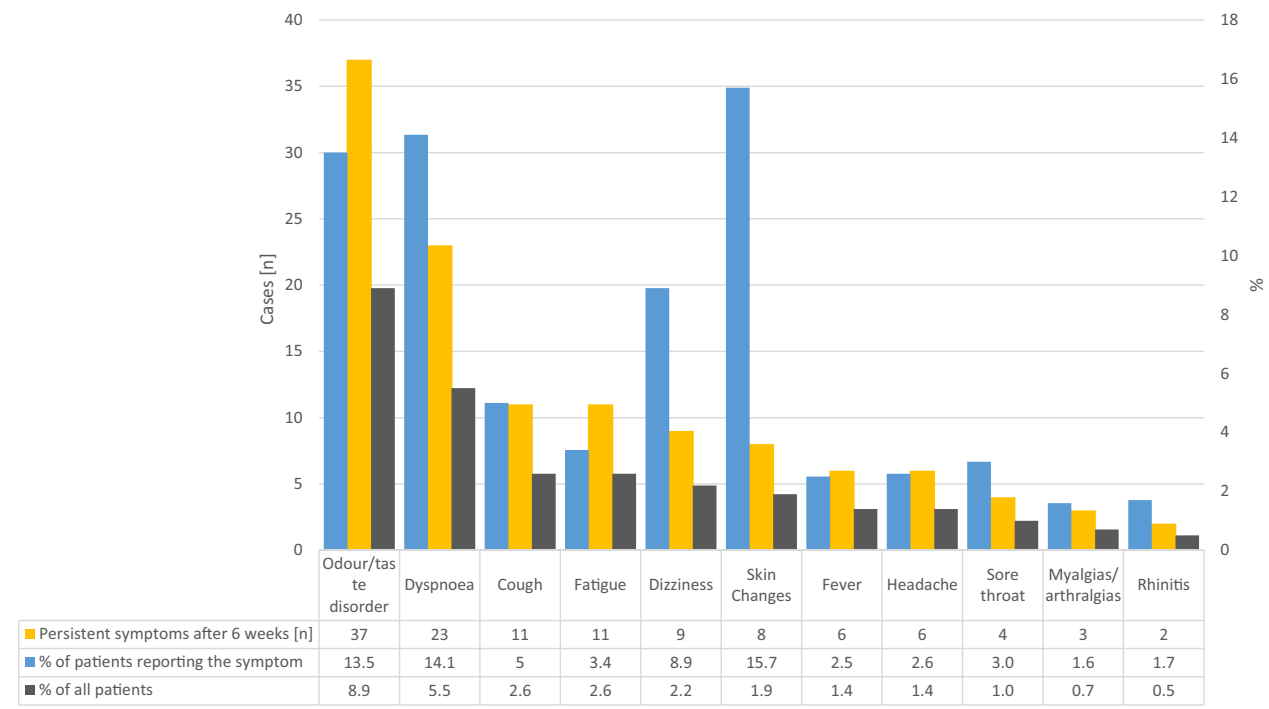

Regarding symptoms, COVID-19 is heterogeneous [24, 25]. We assessed the initial frequency of symptoms in different age groups as well as the duration of symptoms in follow-up calls. The leading symptom in all age groups was fever. On the other hand, more specific symptoms such as odour/taste disorder were reported in only $20 \%$ of subjects as an initial symptom. Generally, in the very young and the very elderly, certain symptoms such as rhinitis or myalgias/ arthralgias are reported less frequently. Remarkably, approximately $9 \%$ of cases interviewed during follow-up reported persisting symptoms for at least 6 weeks from onset.

The strengths of our study are the almost complete investigation of a large regional cohort with a detailed description and analysis of age-specific symptoms and duration of symptoms.

Study limitations include the retrospective design with a potential interviewer or recall bias and uncertain validity of the data regarding the type and duration of symptoms. Moreover, the data were collected during the heyday of the first pandemic wave as part of infection control and containment measures, precluding a thorough planning of the interviews. Also, the follow-up interview could not be conducted within a fixed time frame for each individual but was performed if at least 6 weeks had passed since the reported onset of symptoms, potentially resulting in variation in the timing of the data collected on symptom duration and state of recovery. The data on symptom duration may not be entirely generalizable because mild cases may have been more likely to be contacted than severe cases. As in other studies relying on reported infections, an uncertain number of a- or oligosymptomatic cases may have been missed.

Furthermore, exposure patterns and testing modalities might have changed during the course of the outbreak, such that hospitalizations were more likely to occur at the beginning of the pandemic even in mild cases, whereas PCR testing was initially more restrictive due to a lack of laboratory capacities.

In conclusion, the Regensburg outbreak was characterized by relatively low numbers of cases and fatalities, particularly in elderly patients and those with COVID-19 risk factors. By comparison, the outbreak affected a relatively large proportion of younger individuals. COVID-19 showed a variety of symptoms and varying symptom duration, some of them lasting for weeks. Further prospective research is needed to clarify and confirm the presented data.

Supplementary Information The online version of this article (https:// doi.org/10.1007/s15010-021-01580-2) contains supplementary material, which is available to authorized users.

Acknowledgements We thank Katharina Katz and Jasmin Metz (both Bavarian Health and Food Safety Authority, LGL) for providing epidemiological data on Bavarian SARS-COV-2 cases. We thank the team of the Regensburg Public Health Department and all supporting colleagues for their unremitting efforts.

\section{Compliance with ethical standards}

Conflict of interest None.

\section{References}

1. Johns Hopkins University: https://gisanddata.maps.arcgis.com/ apps/opsdashboard/index.html\#/bda7594740fd40299423467b4 8e9ecf6. Accessed 10 Sept 2020

2. WHO Coronavirus disease (COVID-19) - Weekly Epidemiological Update. 6 September 2020: https://www.who.int/docs/defaultsource/coronaviruse/situation-reports/20200907-weekly-epi-updat e-4.pdf?sfvrsn=f5f607ee_2. Accessed 10 Sept 2020

3. Chen N, Zhou M, Dong X, et al. Epidemiological and clinical characteristics of 99 cases of 2019 novel coronavirus pneumonia in Wuhan, China: a descriptive study. Lancet. 2020;395(10223):50713. https://doi.org/10.1016/S0140-6736(20)30211-7. 
4. Wu Z, McGoogan JM. (2020) Characteristics of and Important Lessons from the Coronavirus Disease 2019 (COVID-19) Outbreak in China: Summary of a Report of 72314 Cases from the Chinese Center for Disease Control and Prevention. JAMA.

5. Zheng Z, Peng F, Xu B, Zhao J, Liu H, Peng J, Li Q, Jiang C, Zhou Y, Liu S, Ye C, Zhang P, Xing Y, Guo H, Tang W (2020) Risk factors of critical \& mortal COVID-19 cases: a systematic literature review and meta-analysis. J Infect 81(2):16-25.

6. WHO Coronavirus disease (COVID-19) Situation Report - 198, 5 August 2020; https://www.who.int/docs/default-source/coron aviruse/situation-reports/20200805-covid-19-sitrep-198.pdf?sfvrs $\mathrm{n}=\mathrm{f} 99 \mathrm{~d} 1754 \_2$. Accessed 10 Sept 2020

7. RKI Falldefinition Coronavirus-Krankheit-2019 (COVID-19) (SARS-CoV-2): https://www.rki.de/DE/Content/InfAZ/N/Neuar tiges_Coronavirus/Falldefinition.pdf?_blob=publicationFile. Accessed 10 Sept 2020

8. RKI Kontaktpersonen-Nachverfolgung bei respiratorischen Erkrankungen durch das Coronavirus SARS-CoV-2 Accessed: 9.9.2020. https://www.rki.de/DE/Content/InfAZ/N/Neuartiges _Coronavirus/Kontaktperson/Management.html. Accessed 10 Sept 2020

9. Kabesch M, Roth S, Brandstetter S, et al. Successful containment of Covid-19 outbreak in a large maternity and perinatal center while continuing clinical service. Pediatr Allergy Immunol. 2020. https://doi.org/10.1111/pai.13265.

10. Bavarian Health and Food Safety Authority, LGL: Situation report. Accessed 24 May 2020

11. Coronavirus Disease 2019 (COVID-19) - Daily Situation Report of the Robert Koch Institute https://www.rki.de/DE/Content/ InfAZ/N/Neuartiges_Coronavirus/Situationsberichte/2020-0524-en.pdf?_blob=publicationFile. Accessed 10 Sept 2020

12. ECDC Communicable disease threats report, 24-30 May 2020, week 22 https://www.ecdc.europa.eu/sites/default/files/docum ents/Communicable-disease-threats-report-30-may-2020.pdf

13. Coronavirus disease (COVID-19) Situation Report - 125 Data as received by WHO from national authorities by 10:00 CEST, 24 May 2020: https://www.who.int/docs/default-source/coronaviru se/situation-reports/20200524-covid-19-sitrep-125.pdf?sfvrs $\mathrm{n}=80 \mathrm{e} 7 \mathrm{~d} 7 \mathrm{f0} \_2$

14. Landkreis Regensburg in Zahlen. https://www.landkreis-regen sburg.de/media/36986/20190912_lkr_in_zahlen.pdf

15. Regensburg in Zahlen. https://www.regensburg.de/fm/121/regen sburg-in-zahlen-2019.pdf

16. Statistik Bayern. https://www.statistik.bayern.de/mam/produkte/ veroffentlichungen/statistische_berichte/a1100c_201644.pdf. Stand 2016. Accessed 11 Sept 2020
17. Bevölkerungsstand Deutschland. https://www.destatis.de/DE/ Themen/Gesellschaft-Umwelt/Bevoelkerung/Bevoelkerungsst and/_inhalt.html. Accessed 11 Sept 2020

18. Bevölkerungsstand Europa. https://www.destatis.de/Europa/DE/ Home/_inhalt.html Accessed 11 Sept 2020

19. Deutsche Stiftung Weltbevölkerung - Aktueller Bevölkerungsstand. https://www.dsw.org/weltbevoelkerung/?gclid=EAIaI QobChMIma3Co7ng6wIVEBd7Ch0i6geQEAAYASAAEgJ_ bPD_BwE. Accessed 11 Sept 2020

20. Fu L, Wang B, Yuan T, et al. Clinical characteristics of coronavirus disease 2019 (COVID-19) in China: a systematic review and meta-analysis. J Infect. 2020;80(6):656-65. https://doi. org/10.1016/j.jinf.2020.03.041.

21. Guenther F, Bender A, Katz K, Kuechenhoff H, Hoehle M (2020) Nowcasting the COVID-19 Pandemic in Bavaria. medRxiv. https://doi.org/https://doi.org/10.1101/2020.06.26.20140210

22. Shah K, Saxena D, Mavalankar D. Secondary Attack Rate of COVID-19 in household contacts: Systematic review. QJM. 2020. https://doi.org/10.1093/qjmed/hcaa232.

23. Jing QL, Liu MJ, Zhang ZB, Fang LQ, Yuan J, Zhang AR, Dean NE, Luo L, Ma MM, Longini I, Kenah E, Lu Y, Ma Y, Jalali N, Yang ZC, Yang Y. Household secondary attack rate of COVID-19 and associated determinants in Guangzhou, China: a retrospective cohort study. Lancet Infect Dis. 2020;20(10):1141-50. https://doi. org/10.1016/S1473-3099(20)30471-0 (Epub 2020 Jun 17 PMID: 32562601 ).

24. Pascarella G, Strumia A, Piliego C, Bruno F, Del Buono R, Costa F, Scarlata S, Agrò FE. COVID-19 diagnosis and management: a comprehensive review. J Intern Med. 2020;288(2):192-206. https ://doi.org/10.1111/joim.13091.

25. Baj J, Karakuła-Juchnowicz H, Teresiński G, Buszewicz G, Ciesielka M, Sitarz E, Forma A, Karakuła K, Flieger W, Portincasa P, Maciejewski R. COVID-19: specific and non-specific clinical manifestations and symptoms: the current state of knowledge. J Clin Med. 2020;9(6):1753. https://doi.org/10.3390/jcm9061753 .PMID:32516940.

26. GENESIS - Online-Datenbank: Bevölkerung: Kreis, Geschlecht, Altersjahre (75)/ Altersjahre (88), Stichtag 31.12.2019. Accessed 27 Nov 2020

Publisher's Note Springer Nature remains neutral with regard to jurisdictional claims in published maps and institutional affiliations. 